\title{
The influence of grid shape and grid size on hydraulic river modelling performance
}

\author{
A. Bomers ${ }^{1}$ (D) R. M. J. Schielen ${ }^{1,2}$. S. J. M. H. Hulscher ${ }^{1}$
}

Received: 9 February 2018 / Accepted: 11 February 2019 / Published online: 21 February 2019

(c) The Author(s) 2019

\begin{abstract}
Grid shape (curvilinear/structured versus triangular/unstructured) and grid size affect model output. In this study structured, unstructured and hybrid grids with a high and low resolution were compared. As a case study, we use the Waal River (with main channel and floodplains). We studied simulated water levels using the six grids, considering equal main channel friction, which enabled to study the isolated effects of grid shape and size. The spread in simulated water levels was found to be rather large with a maximum deviation of $78 \mathrm{~cm}$. Therefore, calibration was performed such that simulated water levels resembled measured water levels by adjusting the main channel friction. This enabled us to draw conclusions on the choice of optimal usage of the grids in engineering studies. Bathymetry accuracy and numerical friction, both as a result of grid resolution, and numerical viscosity as a result of grid shape play a vital role. The analysis shows that unstructured grids are affected most by the calibration which is reflected in the wide spreading of calibrated friction values. From the six grids studied, the hybrid grid with curvilinear grid cells in the main channel and triangular grid cells in the floodplain is recommended for hydraulic modelling since computation time is low, while model output shows sufficient accuracy.
\end{abstract}

Keywords Hybrid grids · Grid resolution · Bathymetry accuracy · Numerical friction · Numerical viscosity

\section{Introduction}

Currently, sophisticated two dimensional horizontal (2DH) models are used to get a detailed and accurate representation of water levels, flood patterns and potential flood prone areas which help to define flood protection measures. Until now, structured curvilinear grids are commonly used for hydraulic modelling to discretize the model domain within the finite difference and finite volume framework (e.g. [19, 26]). In general, curvilinear grid cells give accurate model output with added benefit of allowing cell stretching along the river main channel, while orthogonality (see Sect. 3 for an explanation of the

A. Bomers

a.bomers@utwente.nl

1 University of Twente, Dienstweg 1, Enschede, The Netherlands

2 Ministry of Infrastructure and Water Management-Rijkswaterstaat, Arnhem, The Netherlands 
orthogonality concept) stays within reasonable bounds [18]. However, this grid type has several disadvantages. The use of curvilinear grid cells results in a high resolution in sharp inner bends since grid lines are focused in these bends (Fig. 1) [16]. Under the assumption that in a curvilinear grid the floodplains follow the same trajectory as the main channel course, it is not possible to locally refine or coarsen the grid since the resolution of the floodplain depends on the resolution of the curvilinear grid cells in the main channel. An unnecessary high resolution increases computation time of the model. In addition, the curvilinear cells are restrictive in representing a natural river system with different geometric features such as main channels, bifurcations and floodplains due to the rectangular shape of the grid cells [18].

Other commonly used grid types are unstructured grids in which the entire model domain is discretized by triangles (e.g. [6, 11, 12, 22]). These grids have been widely used with the finite element or finite volume framework [18]. Triangular grids are easy to generate and they overcome the problems of curvilinear grids, since triangular cells are more flexible in shape [18]. However, stretching the triangular grid cells in the flow direction, results in less accurate model output [1]. There are two reasons for the lower accuracy of the model output. Firstly, stretching triangular grid cells in the flow direction results in low orthogonality (see Sect. 3), which can be kept under control by projecting the grid cells on the edge normal vector. Secondly, if the triangular grid cells are elongated, they tend to degenerate into lines and hence the area-edge length ratio is very small resulting in e.g. small time steps.

The advantages and disadvantages of the fully structured and fully unstructured grids leads to the question whether a combination of the two grid types might be a good alternative. A grid in which different grid shapes are used is referred to as a hybrid grid. In this study the hybrid grids have a structured curvilinear grid in the main channel, whereas the floodplains are discretized by triangular grid cells. A question is how such a hybrid grid affects numerical results. Caviedes-Voullième et al. [4] studied the effect of grid structure on model results with the use of a physically-based numerical model for runoff simulation in a mountain catchment. In their study, they found that mesh selection is of great importance since the model output was more sensitive to mesh properties (grid shape and grid size) than to the friction spatial distribution [4]. Horrit et al. [13] studied the effect of mesh resolution and input digital elevation model (DEM) resolution on the predictions of a 2D finite volume model of channel flow. The model was more sensitive to the size of the grid cells than to the resolution of the input DEM [13]. Kernkamp et al. [16] explored whether the application of a hybrid grid results in accurate model output and used the Northwest European Continental Shelf as a case study. Curvilinear grid cells were aligned with the main flow direction coupled with triangles for computational efficiency. For their

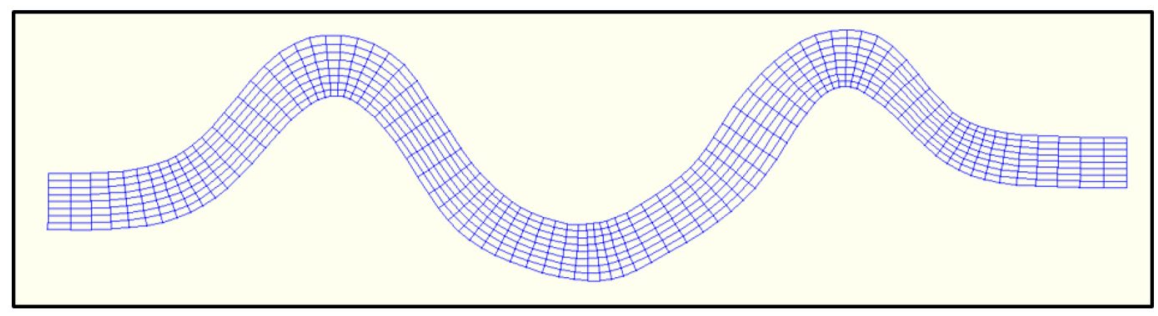

Fig. 1 Grid lines of a curvilinear grid show higher density in inner bends resulting in high resolution in these areas 
application, they found that such a hybrid grid is capable of accurately representing complex boundaries in geometrically complicated areas. The model performance in terms of computation time and accuracy of the hybrid grid was comparable to the performance of a structured grid [16]. Hardy et al. [9] studied the importance of grid resolution for floodplain modelling using seven hybrid grids. In these grids, the main channel was discretized by curvilinear grid cells and the floodplains by triangular grid cells. They found that if resolution increases the inundation extent decreases, and that the effects of the different grid resolutions were at least as important as the surface roughness which is commonly used as typical calibration parameter [9]. Although Hardy et al. [9] made use of a combination of structured and unstructured grids for hydraulic modelling, they did not consider the performance of such a grid compared to fully structured and fully unstructured grids.

Using hybrid grids may be a good alternative of both a fully structured as of a fully unstructured grid (e.g. [2, 9, 16, 18]). However, an extensive comparison on performance between the different grid types with the use of a case study has not been done so far. Therefore, the objective of this paper is to uncover the effects of grid shapes and sizes on model performance for hydraulic flood modelling. Model performance is expressed in terms of computation time, accurate prediction of maximum water levels and accurate simulation of depth-averaged flow velocity profiles in meander bends. To assess the model performance, six different grids are created covering structured, unstructured and hybrid grids with a high and low resolution variant. The grids are calibrated using the 1995 flood event of the Waal river, which is a bifurcation of the Rhine river, such that accurate maximum water levels are predicted by the six different models. The main channel of the Waal river and its floodplains are modelled.

The outline of the paper is as follow. In Sect. 2 the case study of the 1995 Waal river flood event and properties of the numerical model are described. Section 3 provides the different grids considered in this study. Section 4 shows the results focusing on the main differences in model performance. The paper ends with the main conclusions.

\section{Hydraulic modelling: case study Waal}

The 1995 flood event of the Waal river is used as a case study (Fig. 2). The Waal river is a bifurcation of the Rhine river. The upstream boundary is located at the bifurcation point where the Rhine river bifurcates into the Pannerdensch Canal and the Waal river in the Netherlands. The downstream boundary is at the city of Tiel (Fig. 2). The Waal river is

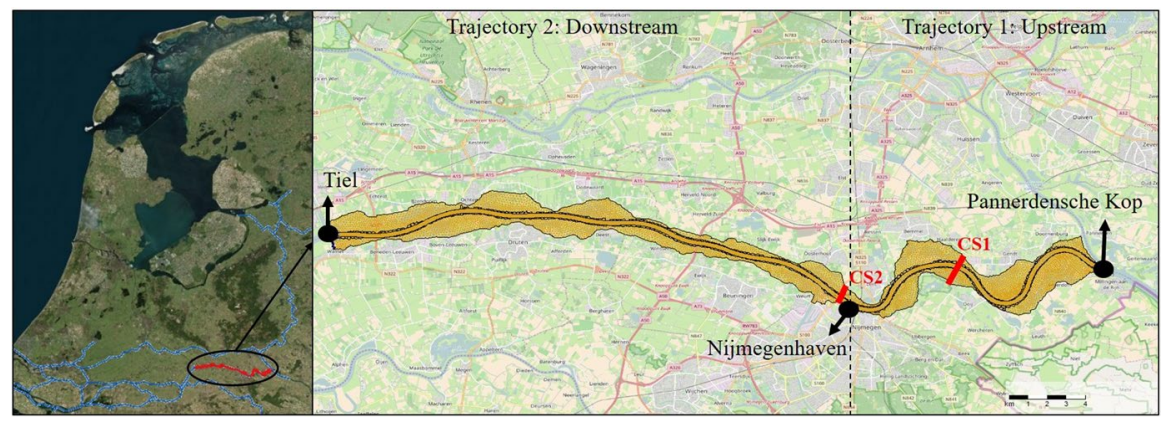

Fig. 2 Location of the Waal river in the Netherlands and the model domain, in which Trajectory 1 represents a meandering stretch and Trajectory 2 a relatively straight stretch of the river. CS1 and CS2 are used to determine the discharge partitioning in the main channel and floodplains in Sect. 4 
used in this study since it is a typical lowland river, ample data is available and schematizations of the study area are available from previous studies. The model domain consists of the main channel of the Waal river and its floodplains. The river has meander bends in the upstream part of the study area and it has a relatively straight course further downstream. For this reason, it is possible to consider the results for both a meandering stretch (Trajectory 1, Fig. 2) as well as for a relatively straight stretch (Trajectory 2, Fig. 2).

The section of the Waal river used in this study has a trajectory length of approximately 46 kilometers, with an average main channel width of 260 meters. No large differences in the main channel width are present. The floodplain widths vary between 20 meters close to Nijmegenhaven (Fig. 2) to 1,650 meters in the upstream meander bends. The total model domain has an area of $66 \mathrm{~km}^{2}$ with a linear length of approximately 40 kilometers. At CS1 and CS2 the discharge partitioning in the main channel and floodplains are evaluated (Sect. 4). These two locations are chosen such that a comparison can be made between a location with wide floodplains (CS1) and almost no floodplains (CS2).

\subsection{Hydraulic model}

Hydraulic modelling is performed with D-Flow Flexible Mesh (FM) in which the 2D Shallow Water equations are solved [8]. The depth-averaged continuity equation and the momentum equations in $\mathrm{x}$ - and $\mathrm{y}$ - direction are given by:

$$
\begin{gathered}
\frac{\partial z}{\partial t}+\frac{\partial[(h+z) u]}{\partial x}+\frac{\partial[(h+z) v]}{\partial y}=0 \\
\frac{\partial u}{\partial t}+u \frac{\partial u}{\partial x}+v \frac{\partial u}{\partial y}=-g \frac{\partial z}{\partial x}-\frac{g u \sqrt{u^{2}+v^{2}}}{C_{z}^{2}(h+z)} \\
\frac{\partial v}{\partial t}+u \frac{\partial v}{\partial x}+v \frac{\partial v}{\partial y}=-g \frac{\partial z}{\partial y}-\frac{g v \sqrt{u^{2}+v^{2}}}{C_{z}^{2}(h+z)}
\end{gathered}
$$

where $u$ and $v$ represent the depth-averaged flow components in $\mathrm{x}$ - and $\mathrm{y}$-directions respectively $(\mathrm{m} / \mathrm{s}), z$ is the water surface elevation $(\mathrm{m}), h$ is the water depth $(\mathrm{m}), g$ represents the constant gravitational acceleration $\left(\mathrm{m} / \mathrm{s}^{2}\right)$, and $C_{z}$ is the Chézy friction coefficient $\left(\mathrm{m}^{1 / 2} / \mathrm{s}\right)$.

\subsection{Computation schemes of the numerical grids}

In this study, for all grid types a finite volume solver on a staggered scheme is used to discretize the Shallow Water equations (Eqs. 1-3). On a staggered scheme, the scalar variables (water level, bed level etc.) at a certain time step are stored in the cell centers of the control volumes whereas the velocity variables are located at the cell faces ([10, 17]). In other words, the velocity variables are shifted half a grid cell in the $\mathrm{x}$ - and $\mathrm{y}$ - direction. Consequently, half of the control volumes of the velocity variables along the boundaries fall outside the model domain and are therefore omitted during the computation. This differs from a collocated scheme arrangement, in which all variables are stored in the same positions. Jones [15] remarks that staggered schemes are commonly used for Shallow Water flow problems. According to Stelling [23], a staggered scheme is very effective 
for the discretization of the Shallow Water equations, since the number of grid points is reduced with a factor four compared to a collocated grid. In addition, a staggered scheme allows for a simple treatment of the boundary conditions and it was found to be more robust compared to a collocated grid. For more information about the application of staggered schemes for Shallow Water flow problems, and the reasons why it has been used in many software packages (e.g. WAQUA, TRIWAQ, D-Flow FM), we refer to [23].

Commonly, rectangular row-columns structured staggered schemes are used to solve the system. However, such a scheme is not applicable for the unstructured and hybrid grids since a rectangular row-columns structure is not present. A number of generalizations of the staggered schemes have been proposed for unstructured grids to retain the mass conservation properties of the classic structured method [20]. The unstructured staggered scheme as described by Kleptsova et al. [17] is used in this study. The continuity equations are solved implicitly while the advection term in the momentum equation is solved explicitly [7]. The advection term makes use of a reconstruction at the cell centre (Perots method, see [20]), which is first-order accurate on unstructured staggered grids. Implicit time integration is used as iterative solver, and the resultant dynamic time step is based on the Courant criteria. In principle, the continuity equation has no time step restriction when using the implicit solver. However, the computed dynamic time step for the advection term is used for both the implicit as the explicit solvers to avoid a calculation scheme staggered in time. This dynamic time step is grid dependent. The Courant number $C$ can be computed with:

$$
C=\frac{u \Delta t}{\Delta x}
$$

where $u$ represents the flow velocity $(\mathrm{m} / \mathrm{s}), t$ the time step (s) and $x$ the length interval in flow direction (m). A maximum Courant number of 0.95 is used. We use the method proposed by Kernkamp et al. [16] to solve the system.

\subsection{Calibration procedure}

The 1995 discharge wave is used as upstream boundary condition and a h(t)-relation is used as downstream boundary condition (Fig. 3) based on measured water levels available at https ://waterinfo.rws.nl provided by the Dutch Ministry of Infrastructure and Water Management. Caviedes-Voullième et al. [4] showed that each grid has its own numerical friction caused by the resolution of the cells and structure of the grid. In their study, they found that mesh coarsening has a similar effect on the discharge wave as friction, i.e. a coarser mesh results in a dampened discharge wave and this effect can even become larger than that generated by physical friction [4]. Applying friction coefficients values selected from literature (e.g. the tables of Chow [5]) may not result in proper results since the numerical friction of the grids is not considered in this way. Therefore, friction coefficients must be calibrated with each grid to compensate for numerical, grid generated friction [4]. In this study, model results are analysed for two situations, namely: one in which an equal main channel roughness is used for each grid (Sect. 4.1) and one in which each grid has its own calibrated main channel friction (Sect. 4.3). For the later situation, the grids are calibrated using hourly measured water levels at Pannerdensche Kop (PK) and Nijmegenhaven (NH) (Fig. 3). To perform the calibration, the open source software OpenDA is used (http://www.openda.org/). With this software, it is possible to select the input parameters that have to be adjusted, such that the desired output is established. The model domain is divided into two trajectories (Fig. 2) in which the main channel friction expressed in Nikuradse roughness coefficient is calibrated such that each trajectory influences 


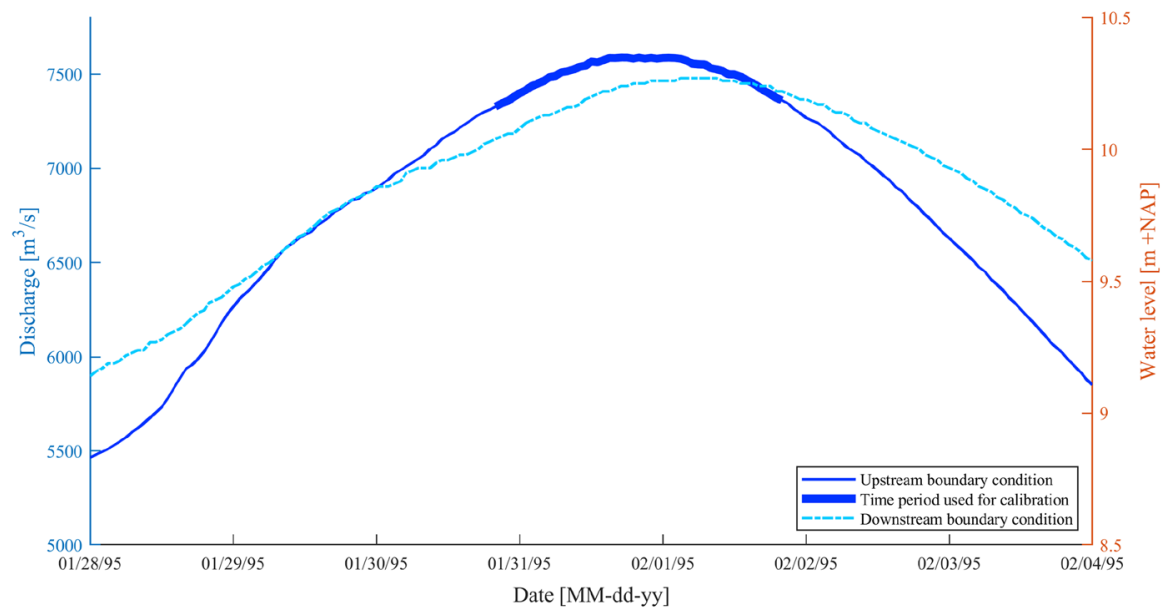

Fig. 3 Discharge wave of the Waal river (upstream boundary condition), time period used for calibration of which hourly measured water levels are available, and water levels at Tiel (downstream boundary condition) during the 1995 flood event

a single measurement location (i.e. PK or NH). The Nikuradse roughness coefficient can be transformed into a Chézy coefficient with the use of the White-Colebrook formula:

$$
C_{z}=18 \times{ }^{10} \log \left(\frac{12 R}{k}\right)
$$

where $C_{z}$ represents the Chézy coefficient $\left(\mathrm{m}^{1 / 2} / \mathrm{s}\right), R$ the hydraulic radius $(\mathrm{m})$ which can be computed by dividing the cross-sectional area by the wetted perimeter, and $k$ represents the Nikuradse roughness coefficient $(\mathrm{m})$. This equation shows that a constant Nikuradse roughness value results in different Chézy coefficients depending on the bathymetry (hydraulic radius) of the river and the local water depth. With the use of the White-Colebrook equation and a constant Nikuradse roughness value, the effect of channel bathymetry and water depth on friction is included, whereas a constant Chézy coefficient would neglect these dependencies. For this reason, Nikuradse roughness values and the White-Colebrook formula (Eq. 5) are used to express the main channel friction in this study.

Calibration is performed on the three days with highest measured water levels (Fig. 3), since the main purpose of the calibration procedure is to ensure that the model is capable of predicting correct maximum water levels. The OpenDA procedure provides a main channel friction of the two trajectories such that the specified water levels at PK and NH are simulated with a Root Mean Square Error $(\mathrm{RMSE})<0.001$. Values of the calibrated friction parameters are given in Sect. 4.3.

\section{Grid properties}

In order to study the consequences of different grid shapes (fully structured, fully unstructured, hybrid) and different sizes (fine, coarse), we constructed six grids. Two structured grids, two unstructured grids and two hybrid grids with different resolutions are 
considered. With this spectrum of grids, we sufficiently cover the wide range of possible grid structures for hydraulic modelling.

Both structured and unstructured grids are commonly used in literature for hydraulic modelling. However, a major disadvantage of structured grids is that the size of the grid cells of the main channel determines the resolution of the floodplains, whereas with unstructured triangular grids it is not possible to stretch the grid cells in flow direction while grid stretching in flow direction can reduce computation time. Therefore, also two hybrid grids are constructed with curvilinear grid cells in the main channel in combination with triangular grid cells in the floodplains to combine the advantages of a structured and an unstructured grid.

For computational efficiency, we use orthogonal grids such that the pressure gradients only depend on two pressure points, which reduces computation time and results in higher model accuracy. The orthogonality principle imposes the following criteria [25]. Firstly, the corners of two adjacent grid cells are situated on a common circle (Fig. 4: red dashed circles). Secondly, the line segment that connects the circumcenter of two adjacent cells (Flowlink, Fig. 4: dashed green line) intersect orthogonally with the interface between them (Netlink) [16]. For triangles, the location of the circumcenter is unique while for curvilinear grid cells there is some freedom in choosing the location of the circumcenter. Orthogonality is defined as the sine of the angle $\varphi$ between a flowlink and a netlink (Fig. 4). Perfect orthogonality is reached if this angle is equal to $90^{\circ}$ (resulting in an orthogonality equal to 1). We strive to have an angle $\varphi$ between $82^{\circ}$ and $98^{\circ}$ for all flowlink and netlink intersections, during the construction of the six numerical grids. For more information about the orthogonalisation principle and examples of (non-) orthogonal grids we refer to Kernkamp et al. [16].

The following six grids are included in the analysis (Fig. 5 and Table 1):

1. Structured curvilinear high resolution (Stru_HR) grid: The model domain is discretized by structured curvilinear cells aligned with the flow direction. The resolution in the main channel equals approximately 12 grid cells in transverse flow direction such that the bathymetry of the cross section is well captured by the grid. The curvilinear grid cells allow cell stretching along the river main channel such that the length of the grid cell in flow direction is larger than the width of the grid cell in transverse flow direction. This cell stretching is beneficial for computation time. However, as a result of the high

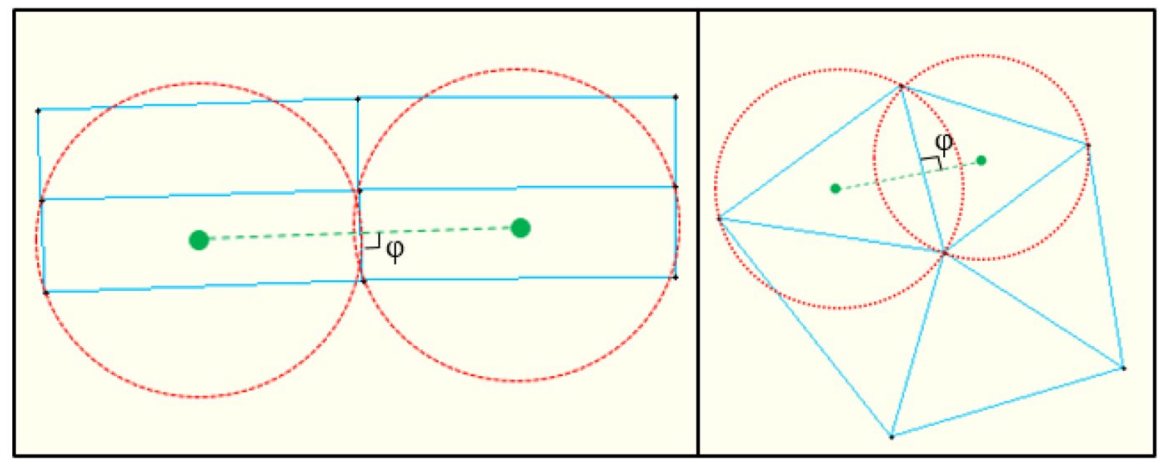

Fig. 4 Example of the orthogonality principle for a structured and an unstructured grid where the grid boundaries represent the netlinks and the green dashed lines the flowlinks 


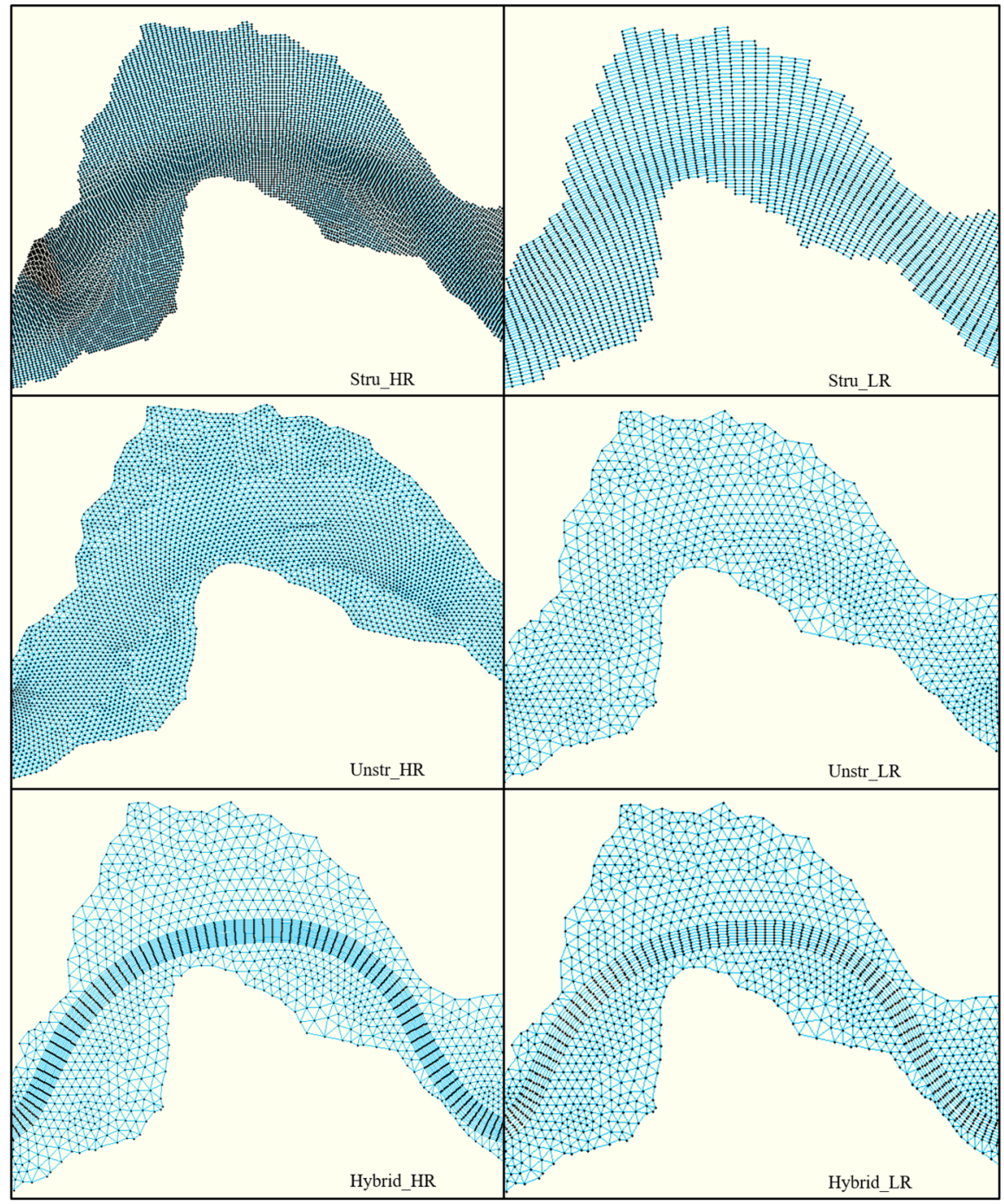

Fig. 5 The six grids considered in this study

resolution in the main channel, also the resolution of the floodplains is high especially in sharp inner bends where grid lines are focused. To avoid that grid cell resolution in sharp inner bends go to zero, the resultant curvilinear grid has less sharp bends than the river course (Fig. 6). For this reason, the structured grid is capable of following the main channel course in straight and slightly meandering river sections. However, it is not capable of following the river course in highly meandering sections with wide floodplains.

2. Structured curvilinear low resolution (Stru_LR) grid: The width and length of the grid cells of the Stru_HR grid are decreased with a factor two. This results in a resolution of six grid cells in the main channel in transverse direction. 


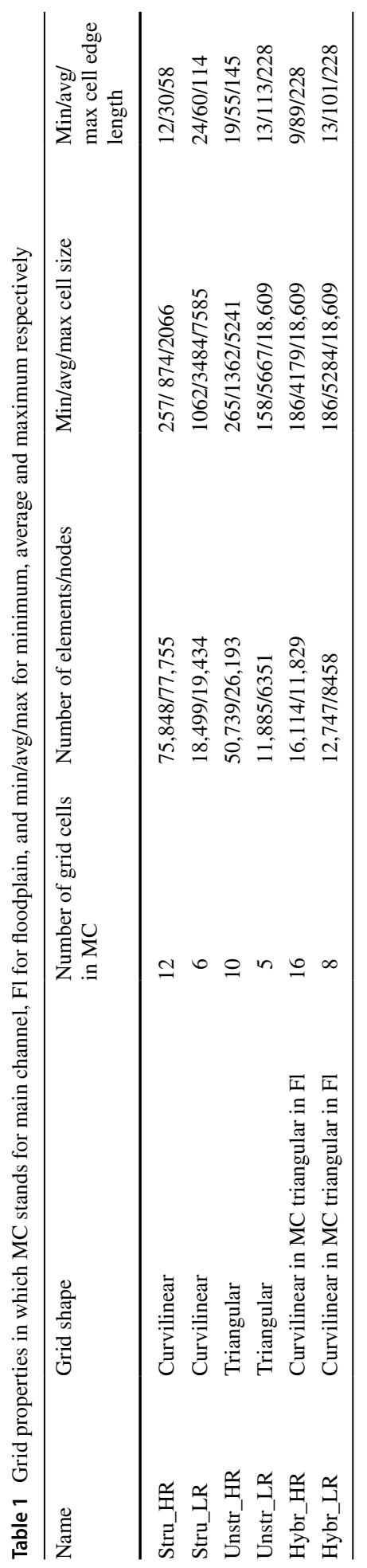


Fig. 6 Part of the Stru_LR grid in a meander bend. In this part of the river, the curvilinear grid cells of the structured grid do not follow the course of the main river (red line), since this will result in grid cell sizes close to zero in meander bends with large floodplains

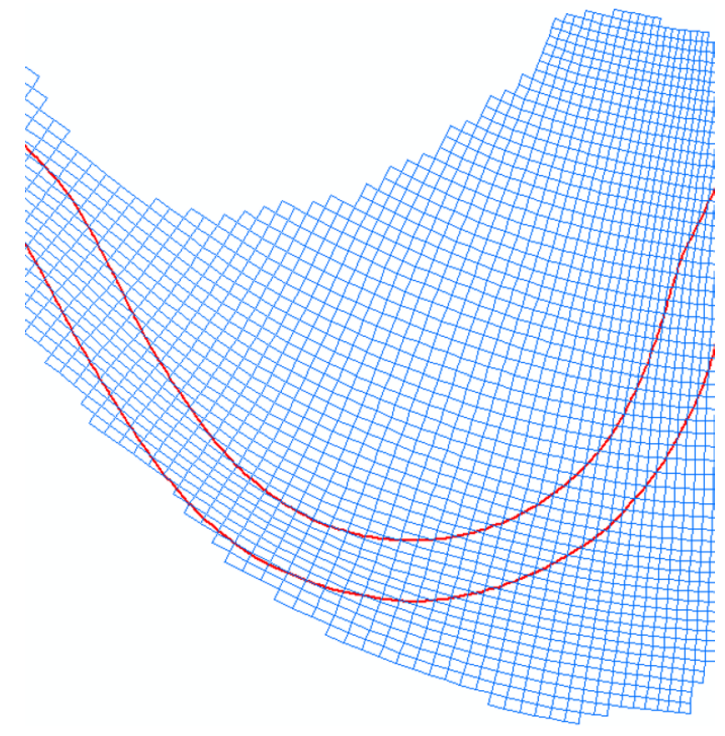

3. Unstructured triangular high resolution (Unstr_HR) grid: The model domain is discretized by triangles. The size of the triangles is adjusted such that approximately 10 grid cells are present in the cross section of the main channel. The resolution of the triangles in the floodplains are identical to the triangles in the main channel. Commonly, unstructured grids are constructed by randomly filling the model domain with triangular grid cells. In this study, firstly the main channel is discretized by triangles, where after the floodplains are discretized. The netlinks located at the boundary of the unstructured grid in the main channel (representing the grid boundary) are used to construct the unstructured grid in the floodplains, such that each triangular grid cell in the main channel is connected to a single triangular grid cell in the floodplains. This process is referred to as alignment with flow direction, resulting in a grid which is structurally well-oriented with the main channel course throughout the model domain. Unstructured grids do not have the problem of high resolution in sharp inner bends as is the case for the Stru_HR and Stru_LR grids. However, the high resolution of the triangular grid in the main channel still results in a high resolution in the floodplains.

4. Unstructured triangular low resolution (Unstr_LR) grid: The resolution of the Unstr_HR grid is decreased with a factor two in both the main channel as the floodplains. The same method as for the Unstr_HR grid is used to ensure alignment with flow direction. A disadvantage of this grid is that the relatively low resolution in the floodplains results in a low resolution in the main channel of approximately five cells in transverse flow direction.

5. Hybrid high resolution (Hybr_HR) grid: This grid is a mixture of the Stru_HR and Unstru_LR grids. The grid has 16 curvilinear grid cells in the transverse direction of the main channel aligned with the flow direction. The floodplains are discretized by triangles in which the size of the triangles is adjusted to the length of the curvilinear grid cells such that each triangular grid cell at the main channel-floodplain boundary is connected with a single curvilinear grid cell. The netlinks located at the boundary of the curvilinear grid are used to construct the triangular grid of the floodplains. This grid combines the advantages of high resolution in transverse flow direction in the main 
channel of the Stru_HR grid and the low resolution in the floodplains of the Unstr_LR grid.

6. Hybrid low resolution (Hybr_LR) grid: This grid is almost identical to the Hybr_HR grid. Only the width of the curvilinear grid cells is increased with a factor two, resulting in eight grid cells in the transverse direction of the main channel. The triangular grid in the floodplains is identical to the triangular grid of the Hybr_HR and Unstr_LR grids.

\section{Results}

In this section, the model results of the six grids presented in Sect. 3 are analysed. Firstly, model results with an equal main channel friction for the six grids are given (Sect. 4.1) to show the differences in simulated water levels solely caused by the use of different grid types. Then, the model performance after calibration and the effects of grid size and grid shape on calibrated main channel friction values are presented (Sects. 4.2 and 4.3, respectively). In Sect. 4.4 the depth-averaged velocities in a sharp meander bend are presented.

\subsection{Equal main channel friction}

The Stru_HR grid, having the highest resolution, was calibrated following the procedure described in Sect. 2.3, resulting in simulated water levels close to measurements (maximum deviation of $1 \mathrm{~cm}$ ). The calibrated main channel friction values in trajectories 1 and 2 (Fig. 2) are used to simulate the 1995 flood event with the remaining five grids. In this way, six simulations are performed in which the settings are kept constant. Only the grid is different.

The six model runs resulted in a discharge exceeding the bank full-discharge of the main channel throughout the model domain. Hence, the floodplains discharged water during the entire simulations. In the upstream part of the model domain, where floodplains are wide, the discharge in the main channel and in the floodplains is more or less equal, while in the downstream part, where floodplains are much smaller, approximately $75 \%$ of the total discharge flows in the main channel. Although the general flood patterns are more or less identical predicted by the six grids, the simulated maximum water levels differ significantly (Tables 2 and 3). In general, there are three factors related to the grid properties that influence the simulated water levels:

- Bathymetry accuracy caused by grid resolution: The resolutions of the grids determine how well the bathymetry of the river cross section is captured by the model based on an input DEM. A high resolution results in a good representation of the bathymetry, while a low resolution results in a strongly schematized bathymetry. A strongly schematized river cross section may result in an underestimation or an overestimation of the cross-sectional area of the river and hence its discharge capacity. This depends on the bathymetry of the river cross section and the location of the grid edges (Fig. 7). As a result of these overestimations and underestimations of the cross-sectional area, water levels are underestimated or overestimated respectively. 
Table 2 Predicted maximum water levels (Max WL) at PK and discharge partitioning (Q) at CS1 (Fig. 2) with constant main channel friction among the six grids

\begin{tabular}{llll}
\hline Grid & $\begin{array}{l}\text { Max WL }(\mathrm{m} \\
\text { + NAP })\end{array}$ & $\begin{array}{l}\text { Q main channel } \\
\left(\mathrm{m}^{3} / \mathrm{s}\right)\end{array}$ & $\begin{array}{l}\text { Q flood- } \\
\text { plains } \\
\left(\mathrm{m}^{3} / \mathrm{s}\right)\end{array}$ \\
\hline Stru_HR & 15.84 & 3851 & 3733 \\
Stru_LR & 16.13 & 4092 & 3492 \\
Unstr_HR & 15.35 & 3593 & 3989 \\
Unstr_LR & 15.48 & 3471 & 4111 \\
Hybr_HR & 15.50 & 3722 & 3860 \\
Hybr_LR & 15.71 & 3700 & 3882 \\
\hline
\end{tabular}

Table 3 Predicted maximum water levels (Max WL) at NH and discharge partitioning (Q) at CS2 (Fig. 2) with constant main channel friction among the six grids

\begin{tabular}{llll}
\hline Grid & $\begin{array}{l}\text { Max WL }(\mathrm{m} \\
\text { +NAP })\end{array}$ & $\begin{array}{l}\text { Q main channel } \\
\left(\mathrm{m}^{3} / \mathrm{s}\right)\end{array}$ & $\begin{array}{l}\text { Q flood- } \\
\text { plains } \\
\left(\mathrm{m}^{3} / \mathrm{s}\right)\end{array}$ \\
\hline Stru_HR & 13.53 & 5564 & 2018 \\
Stru_LR & 13.65 & 5427 & 2156 \\
Unstr_HR & 13.67 & 5501 & 2079 \\
Unstr_LR & 13.87 & 5853 & 1727 \\
Hybr_HR & 13.62 & 5515 & 2065 \\
Hybr_LR & 13.65 & 5476 & 2104 \\
\hline
\end{tabular}

- Numerical friction caused by grid resolution: Caviedes-Voullième et al. [4] and Schubert et al. [21] found that, as a grid is coarsened, numerical friction increases. Grid coarsening has the same effect on model results as increasing the bed friction. A coarser grid results in dampening of the discharge wave and in a delay of the peak flow. Furthermore, simulated water levels increase. These consequences as a result of grid coarsening is referred to as numerical friction.

- Numerical viscosity created by grid shape: Caviedes-Voullième et al. [4] discuss that grids that follow the direction of the flow (i.e. that have grid edges perpendicular and parallel to the flow direction) have lower numerical viscosity compared to grids that do not follow the river course. Also numerical viscosity has the same effect on model results as increasing the bed friction. Numerical viscosity thus also results in attenuation of the discharge wave and in an increase in the simulated water levels.

Comparing the water levels generated by the six grids (Tables 2 and 3), we find that the low resolution variants of each grid type predict higher water levels compared to the high resolution variants, throughout the model domain. As a grid is coarsened, numerical friction increases and hence water levels increase.

Moreover, we find that the structured grids predict higher water levels at PK and the unstructured grids at NH. This is a result of the numerical viscosity created by grid shape. The upstream part of the model domain has large meander bends. As explained in Sect. 3 and Fig. 6, the curvilinear structured grids are not capable of following these meanders and hence the flow direction differs from the course of the grids (Fig. 8). This results in an increase in the numerical viscosity and consequently in an increase in the water levels compared to a grid which is capable of following the river course. The unstructured grids 


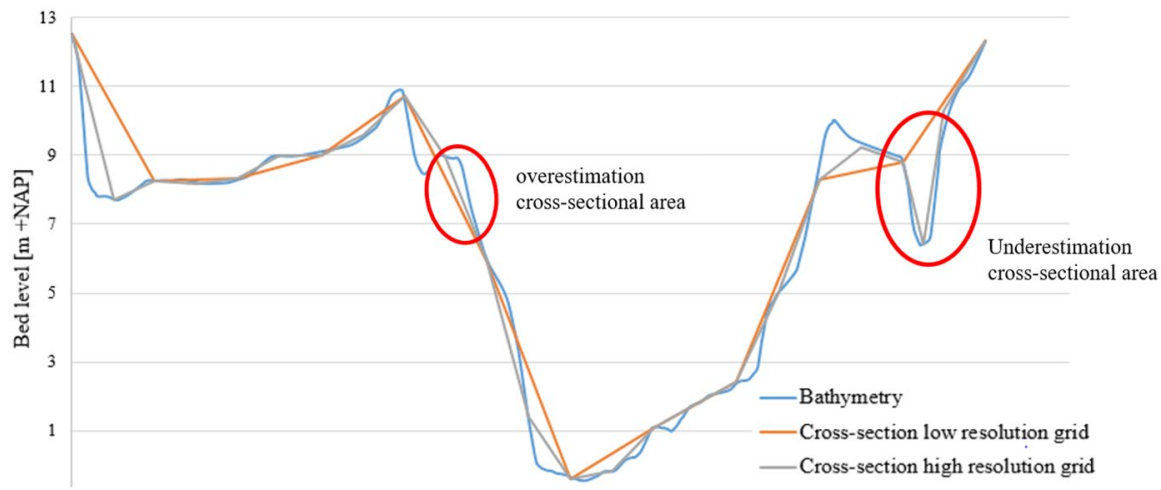

Fig. 7 Representation of the bathymetry of the river (main channel and floodplains) and corresponding representations of a high resolution and a low resolution grid

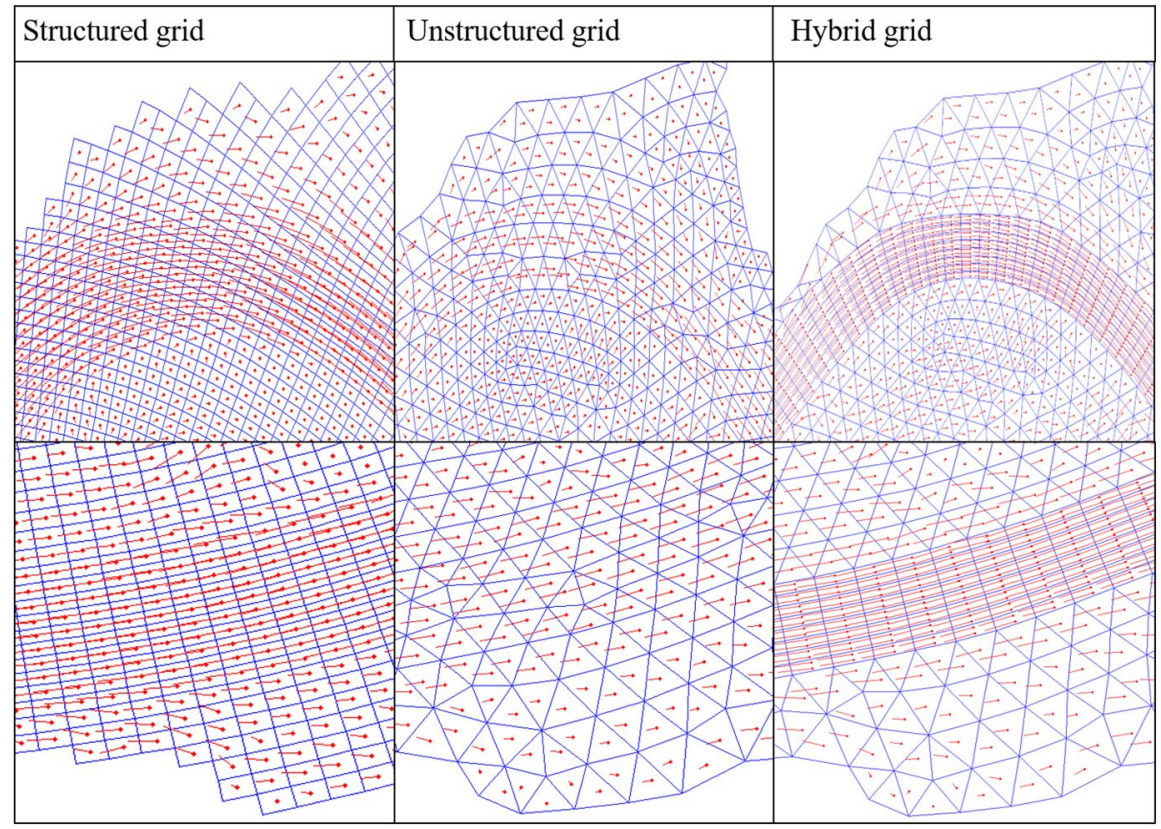

Fig. 8 Flow directions of structured, unstructured and hybrid grids in a meander bend and straight river

and the hybrids grids are better oriented with the flow direction in the upstream part of the model domain (Fig. 8), resulting in lower numerical viscosity compared to the structured grids and thus to lower simulated water levels at PK. Contrarily, in the downstream part of the model domain, the river has a relatively straight course without great meander bends. For this reason, the curvilinear grid cells of the structured and hybrid grids are capable of following the course of the river (Fig. 8), resulting in low numerical viscosity. Although the unstructured grids are structurally well-oriented with the flow direction, triangular grid cells do not have grid edges perpendicular and parallel to the flow direction like the 
curvilinear grid cells of the structured and hybrid grids (Fig. 8). Therefore, the unstructured grids have higher numerical viscosity in the downstream part of the model domain, resulting in higher water levels at $\mathrm{NH}$ compared to the other grid types.

Comparing the simulated maximum water levels and discharge partitioning in the main channel and in the floodplains of the six grids (Tables 2 and 3), we find that the grid that predicts highest water levels as a result of numerical viscosity (structured grids in upstream part and unstructured grids in downstream part of the Waal river), also predicts the highest discharge in the main channel. We would expect a similar trend for numerical friction: an increase in numerical friction results in an increase in the simulated water levels and to an increase in the discharge of the main channel. This trend between high and low resolution grids is not present (i.e. the low resolution grid with high numerical friction does not necessarily result in an increase in the discharge in the main channel). This trend is not present since also bathymetry accuracy influences the discharge capacity of the main channel. An underestimation of the cross-sectional area of the main channel caused by a low resolution grid may result in an underestimation of the main channels discharge capacity. Also the opposite may hold, in which an overestimation of the cross-sectional area may result in an overestimation of the discharge capacity.

In general, we find that the use of different grid shapes and grid sizes has a larger effect in river sections where floodplains are wide compared to sections where floodplains are much smaller. Comparing the differences in predicted water levels by the six grids in the upstream part $(\mathrm{PK})$ and downstream part $(\mathrm{NH})$, shows that the range of maximum water levels is much larger at PK than at $\mathrm{NH}$. The maximum water levels at PK have a range of $0.65 \mathrm{~m}$, while the range at $\mathrm{NH}$ is just $0.34 \mathrm{~m}$. This larger range in the upstream part of the Waal river is also found for the discharge partitioning. At CS2, where floodplains are small, the maximum deviation in discharge in the main channel equals $426 \mathrm{~m}^{3} / \mathrm{s}$, while the deviation in the discharge in the main channel at CS1 equals approximately $620 \mathrm{~m}^{3} / \mathrm{s}$.

\subsection{Model performance after calibration}

For this case, the six grids were calibrated on two separate trajectories, following the procedure described in Sect. 2.3. The model results after calibration are compared based on model accuracy and computation time. No significant difference in accuracy among the different models was found, since the RMSE criteria (RMSE $<0.001$, see Sect. 2.3) was met for all models at both measurement locations. We found that the six calibrated models are capable of simulating maximum water levels at both $\mathrm{PK}$ and $\mathrm{NH}$, which were used during the calibration procedure, with a maximum deviation of one centimeter compared to measurements. Since the water depth at PK and NH during the 1995 flood event was larger than $10 \mathrm{~m}$ at both measurement stations, a deviation of $1 \mathrm{~cm}$ is assumed to be acceptable.

Although the models predicted almost the same maximum water levels, the computation times of the six models differ in the order of hours to minutes (Table 4). Especially the computation time of the Stru_HR grid is much higher compared to the other grids because of the large number of grid cells (Table 1). Surprisingly, the computation time of the Hybr_ LR and Hybr_HR grids are lower than that of the Unstr_LR grid, although the hybrid grids have more grid cells. This can be explained by the curvilinear grid cells in the main channel of the hybrid grids which are aligned with the flow direction. Since the curvilinear grid cells are aligned with the flow direction, the cell edge parallel to the flow is larger than the cell edge perpendicular to the flow. This alignment in flow direction of the curvilinear grid cells in the main channel of the hybrid grids results in a larger $\Delta x$ in flow direction 
Table 4 Computation time $(\mathrm{T})$, average time step $(\Delta \mathrm{t})$ and calibrated Nikuradse main channel roughness height $\left(\mathrm{N}_{\mathrm{k}}\right)$

\begin{tabular}{llrrllll}
\hline Grid & T (h:min:s) & T/T $\mathrm{T}_{\text {ref }}$ & $\Delta \mathrm{t}(\mathrm{s})$ & $\begin{array}{l}\mathrm{N}_{\mathrm{k}}(\mathrm{m}) \text { Tra- } \\
\text { ject. } 1\end{array}$ & $\begin{array}{l}\mathrm{N} / \mathrm{N}_{\text {ref }} \text { Traject. } \\
1\end{array}$ & $\begin{array}{l}\mathrm{N}_{\mathrm{k}}(\mathrm{m}) \text { Tra- } \\
\text { ject. } 2\end{array}$ & N/N $\mathrm{N}_{\text {ref }}$ Traject. 2 \\
\hline Stru_HR & $1: 51: 44$ & & 5.5 & 1.66 & & 0.85 & \\
Stru_LR & $0: 09: 47$ & 0.09 & 14.6 & 0.63 & 0.38 & 0.65 & 0.76 \\
Unstr_HR & $1: 29: 22$ & 0.80 & 3.7 & 5.44 & 3.28 & 0.53 & 0.62 \\
Unstr_LR & $0: 29: 22$ & 0.26 & 1.9 & 4.92 & 2.96 & 0.29 & 0.34 \\
Hybr_HR & $0: 14: 03$ & 0.13 & 6.9 & 3.67 & 2.21 & 0.70 & 0.82 \\
Hybr_LR & $0: 13: 02$ & 0.12 & 5.7 & 2.85 & 1.72 & 0.60 & 0.71 \\
\hline
\end{tabular}

Traject. 1 indicates the upstream part of the model domain and Traject. 2 the downstream part. The Stru_ HR grid is used as reference (ref)

compared to the triangular grid cells of the unstructured grid. This larger $\Delta x$ results in a larger time step $\Delta t$ (Eq. 4). We can thus conclude that as a result of the curvilinear grid cells in the main channel, the computation of the hybrid grids is more stable (larger time steps for the same Courant numbers) compared to the unstructured grids, resulting in an increase in the average time step. We can therefore state that the differences in average time step as a result of the maximum Courant number (0.95, Sect. 2.2), determines the differences in computation time of the six models.

\subsection{Effects of grid size and structure on calibration}

Section 4.1 showed that different water levels are simulated by the six different grid types if the same main channel friction values are used. These differences in water levels are caused by the three factors (1) bathymetry accuracy, (2) numerical friction and (3) numerical viscosity. During the calibration procedure, the main channel friction values are calibrated such that the total friction of the model (representing the physical friction and the numerical friction generated by grid size and grid shape) is accurately captured, resulting in accurately simulated water levels (Sect. 4.2). Since the structured grids have high numerical viscosity in meandering parts of the river, the calibrated main channel friction is low in the upstream part of the river. Contrarily, in the downstream part of the model domain, where the river is quite straight, the unstructured grids have higher numerical viscosity compared to the structured and hybrid grids. Therefore, the unstructured grids have low calibrated main channel friction values in straight parts of a river course. Moreover, we find that for each grid type lower main channel friction values are calibrated for the low resolution variants compared to the high resolution grids throughout the model domain. A decrease in resolution results in an increase in the numerical friction and hence in a decrease of the computed main channel friction.

Although the flood propagation of the six models shows a similar pattern (i.e. timing of maximum discharge, Fig. 9), the predicted discharge in the main channel and floodplains differ significantly at CS1 (Table 5 and Fig. 9). We find that the differences in discharge partitioning is larger if calibrated main channel friction values are used compared to the situation in which an equal main channel friction was used (Sect. 4.1). Section 4.1 showed that the Unstr_LR grid simulated maximum water levels at PK which were approximately $30 \mathrm{~cm}$ higher than measurements. Therefore, a low main channel 

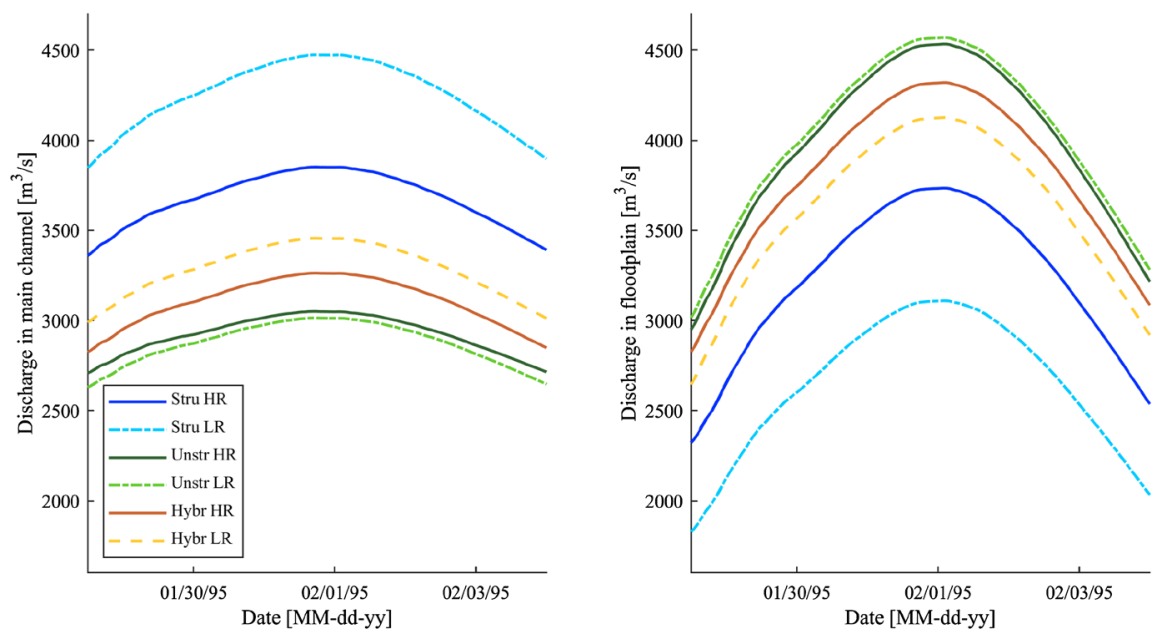

Fig. 9 Discharges in the main channel and floodplains at location CS1 (Fig. 2)

Table 5 Predicted discharge partitioning (Q) at CS1 and CS2 (Fig. 2) with calibrated main channel friction for each grid

\begin{tabular}{lllll}
\hline Grid & $\begin{array}{l}\text { Q main channel }\left(\mathrm{m}^{3} / \mathrm{s}\right) \\
\text { CS1 }\end{array}$ & $\begin{array}{l}\text { Q floodplains }\left(\mathrm{m}^{3} / \mathrm{s}\right) \\
\text { CS1 }\end{array}$ & $\begin{array}{l}\text { Q main channel }\left(\mathrm{m}^{3} / \mathrm{s}\right) \\
\text { CS2 }\end{array}$ & $\begin{array}{l}\text { Q floodplains } \\
\left(\mathrm{m}^{3} / \mathrm{s}\right) \text { CS2 }\end{array}$ \\
\hline Stru_HR & 3851 & 3733 & 5564 & 2018 \\
Stru_LR & 4475 & 3108 & 5455 & 2127 \\
Unstr_HR & 3050 & 4533 & 5544 & 2037 \\
Unstr_LR & 3014 & 4569 & 5890 & 1691 \\
Hybr_HR & 3263 & 4319 & 5554 & 2026 \\
Hybr_LR & 3456 & 4127 & 5519 & 2061 \\
\hline
\end{tabular}

friction was computed during the calibration, which increases the discharge capacity of the main channel. The opposite accounts for the unstructured and hybrid grids which simulated water levels lower than measurements. Therefore, the main channel friction was increased during the calibration which decreases the capacity of the main channel. Consequently, the discharge in the floodplains increases.

We can thus state that the model calibration influences the discharge capacity of the main channel and hence the discharge partitioning between the main channel and floodplains during flood events. This specifically applies for river sections with wide floodplains. In the downstream part of the Waal river, where floodplains are small, the calibration procedure did not result in large changes in the main channel friction of the six grids since no large differences in predicted water levels by the six grids was observed if an equal main channel friction was used (Table 3). Hence, there is also no large change in the discharge partitioning between the main channel and the floodplains.

From the analysis, we find that unstructured grids tend to be most sensitive to the three factors influencing predicted water level and consequently calibrated main channel friction, since the range of calibrated main channel friction along the two trajectories of the Waal river is relatively wide [Nikuradse roughness height of between 0.29 and $5.44 \mathrm{~m}$ (Table 4)] 
Table 6 Main properties of the six grids, in which BA refers to bathymetry accuracy, NF to numerical friction and NV to numerical viscosity

\begin{tabular}{lll}
\hline Grid & $\mathrm{V}_{\max }(\mathrm{m} / \mathrm{s})$ & $\begin{array}{l}\text { Physical } \\
\text { processes } \\
\text { captured? }\end{array}$ \\
\hline Stru_HR & 2.34 & Yes \\
Stru_LR & 2.34 & No \\
Unstr_HR & 2.68 & Yes \\
Unstr_LR & 2.48 & No \\
Hybr_HR & 3.05 & No \\
Hybr_LR & 2.63 & Yes \\
\hline
\end{tabular}

compared to the ranges of the other grid types. The structured curvilinear grids tend to be less sensitive to the factors [Nikuradse roughness height of between 0.63 and $1.66 \mathrm{~m}$ (Table 4)]. The hybrid grids combine the effects of the structured and unstructured grids. This explains why the calibrated friction values of the hybrid grid falls within the calibrated range of the two other grid types [Nikuradse roughness height of between 0.60 and $4.92 \mathrm{~m}$ (Table 4)].

In Sect. 4.2, we found that all grids were capable of predicting maximum water levels of the 1995 flood event with a maximum deviation of $1 \mathrm{~cm}$ compared to measurements. However, the question arises whether the unstructured grids, with large calibrated main channel friction in the meandering part of the river, are also capable to predict water levels at other discharge stages accurately. It is likely that the unstructured grids do not accurately predict water levels during low flow in meandering rivers as a result of the high calibrated friction in the main channel. During low flow, water only flows in the main channel. Consequently, the calibrated main channel friction has a larger influence on the simulated water levels compared to high flow situations, in which also the floodplains discharge water. Since water was flowing in the floodplains during the entire simulations presented in this study, the high calibrated main channel friction in the meandering part of the river of the unstructured grids will most likely result in an overestimation of the simulated water levels during low flow. Therefore, calibration at different discharge stages is recommended, resulting in a main channel friction-discharge relation which can be used to perform hydraulic computations accurately.

\subsection{Velocity magnitudes}

Although the six grids were capable of predicting maximum water levels with high accuracy after calibration, it is unknown to what extent the physical processes are well captured by the calibrated models. Simulated water levels are commonly used to validate the model performance. However, the model should also correctly simulate flow velocities based on physical processes that are generated by the geometry. This is important if the hydraulic model is coupled to e.g. prediction of morphodynamic changes of the river or vegetation development in the floodplains. To study this, depth-averaged flow velocities (at maximum water levels) in the meander bend near measurement station NH and near CS2 (Fig. 2) are qualitatively compared with experimental data provided in literature. Table 6 summarizes the results.

From literature it is known that high flow velocities occur near the outer bend, while flow velocities are lower in the inner bend [3, 14]. Sukhodolov [24] measured 
depth-averaged flow velocities in a meander bend and found that the flow pattern at the entrance of the bend is more or less symmetrical while close to the bend apex, the flow gradually becomes asymmetric with maximum velocities close to the outer bank [24]. The measurements show that at the bend apex the flow remains attached to the outer bank and downstream from the apex a narrow region of flow stagnation develops along the outer bank [24].

Figure 10 shows that the general pattern of high depth-averaged flow velocities (at maximum water levels) in the main channel and relatively low flow velocities in the floodplains is predicted by the different grid types. However, in more detail, several differences can be observed. Firstly, the high resolution grids result in higher maximum flow velocities compared to the low resolution grids, except for the structured grids where maximum flow velocities remain similar (Table 6). The low resolution grids have a lower calibrated main channel friction compared to the high resolution grids. Ignoring numerical friction and numerical viscosity generated by the grids itself, we would expect higher maximum flow velocities to occur for the low resolution grids, because of its low calibrated main channel friction values. Since this is not the case, we conclude that the lower maximum flow velocities of the low resolution grids are entirely a result of the numerical friction caused by grid resolution.

Sukhodolov [24] shows in his measurements a gradual decrease in flow velocity from outer towards inner bend. Most grids tend to predict maximum flow velocities at the outer bend. Only the Stru_LR and Unstr_LR grids provide different results. Maximum flow velocities of the Stru_LR grid occurs at the middle part and inner bend of the meander which contradicts with the physical processes and with measurements given in Sukhodolov [24]. The Unstr_LR grid results in an even more unrealistic pattern of flow velocities caused by the low resolution in the main channel transverse direction (only 5 grid cells). This low resolution results in an extremely discretized bathymetry and hence the model is not capable of correctly predicting flow velocities. The Unstr_LR grid predicts high depth-averaged flow velocities (1.83-2.24 m/s) over the entire cross-section of the main channel at location CS2 (bend apex). This results in a higher width and depthaveraged flow velocity compared to the other grid types. As a result, the discharge in the main channel at CS2 of the Unstr_LR is greater than those of the other grids (Table 5). Also the opposite occurs at several locations, where velocities in the main channel are underestimated and velocities in the floodplains are overestimated by the Unstr_LR grid (Fig. 11). Consequently, the Unstr_LR grid is not capable of correctly modelling the discharge partitioning between the main channel and the floodplains.

Moreover, we find that the high resolution in the transverse direction of the main channel of the Hybr_HR grid (16 grid cells, Table 1) results in flow separation in the meander bend (Fig. 10). A large part of the discharge wave flows towards the outer bend, while a part remains attached at the inner bend. This results in high velocities at the outer bend $(3.05 \mathrm{~m} / \mathrm{s})$ and the inner bend $(2.50 \mathrm{~m} / \mathrm{s})$, while in the middle part of the main channel flow velocities are much lower $(0.68 \mathrm{~m} / \mathrm{s})$. The unrealistic flow pattern predicted by the Hybr_ HR grid is most probably a result of the high width-length ratio of the curvilinear grid cells in the main channel. Generally, a maximum ratio of 1:5 is applied as a rule of thumb. The Hybr_HR grid has at some locations a much higher ratio up to 1:9. The high resolution in transverse direction of the main channel ensures that changes in flow characteristics in this transverse direction can be accurately captured by the model. However, since some grid cells have a length which is nine times greater than its width, the grid is most likely not capable of correctly modelling rapid flow changes in the direction of the flow, specifically in the case of sharp meandering bends. 


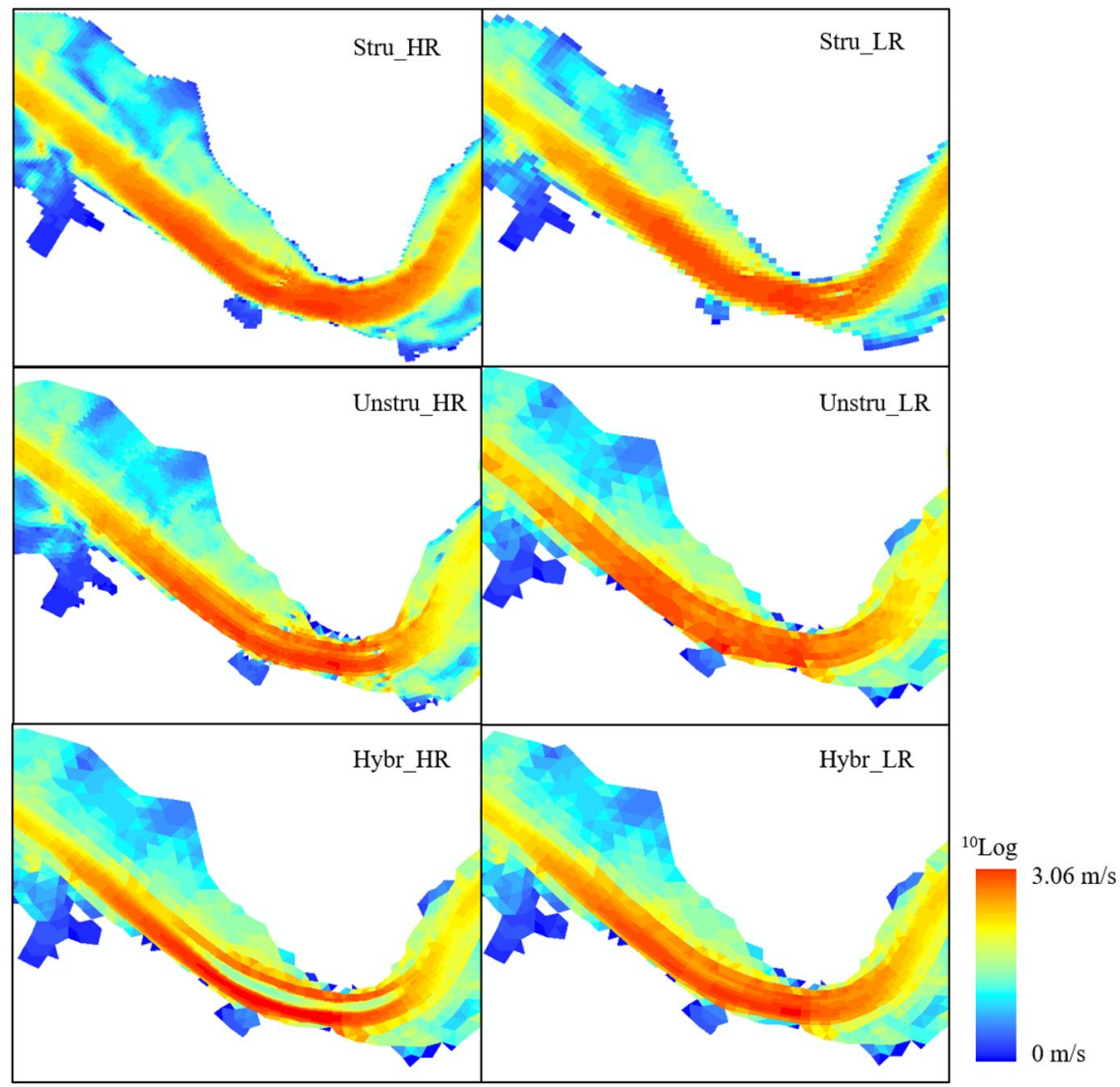

Fig. 10 Depth-averaged flow velocities at the centers of the flow elements at the time of maximum water level plotted on a log-scale

From this analysis, we presume that two aspects are of high importance to correctly predict flow velocities in the main channel, and as a result the discharge partitioning between the main channel and the floodplains. These two aspects are: (1) the resolution in the main channel transverse direction, and (2) the width-length ratio of the curvilinear grid cells in the main channel. The cells of the Stru_LR grid and specifically for the Unstr_LR grid have sizes larger than the spatial scale of the physical processes, whereas the width-length ratio of the Hybr_HR grid is too large. Therefore, these three grids are not capable of correctly representing the depth-averaged flow velocity profiles in a meander bend. More research is recommended to verify these findings.

\section{Conclusions}

In this paper, we studied the effect of grid shape and grid size on computation time and on model accuracy and we compared structured, unstructured and hybrid grids with each high and low resolutions. We found that all grids are capable of predicting accurate water levels 


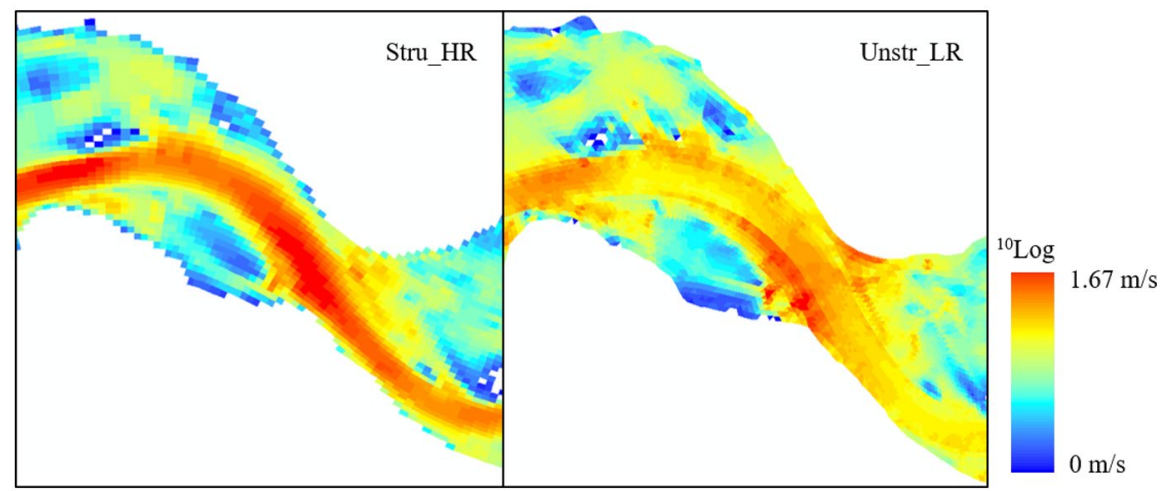

Fig. 11 Depth-averaged flow velocities at the centers of the flow elements in a part of the river where the Unstr_LR grid highly underestimates the flow velocities in the main channel and overestimates the flow velocities in the floodplains compared to the Stru_HR grid which predicts the general flow velocity pattern accurately

with calibrated main channel friction values. However, a large range of calibrated main channel friction and computation time between the different grid types was found. We conclude that three factors influence simulated water levels and are thus important during the determination of the calibrated main channel friction, namely (1) bathymetry accuracy, and (2) numerical friction which are both caused by grid resolution, and (3) numerical viscosity which is caused by the grid shape. Low resolution grids are not able to correctly represent the cross-sectional area of the river as a result of low bathymetry accuracy. Consequently, the discharge capacity of the river is not correctly predicted. Furthermore, low resolution grids result in high numerical friction and hence in high simulated water levels. Moreover, it was found that grids that are well-aligned with the flow direction have low numerical viscosity. Numerical viscosity is predominant in meandering rivers, where the curvilinear grid cells of the structured grids were not capable of following the course of the main channel and hence the flow direction. In addition, it was found that the unstructured grids are most affected by the three factors since the range of calibrated main channel friction was larger for these grids than those of the hybrid and structured grids.

Furthermore, we can conclude that the pattern of depth-averaged flow velocities in a meander bend depends on the shape and size of the grid cells. If resolution in transverse direction of the main channel is too low, the physical processes are not accurately captured by the model. In addition, a too high width-length ratio of the curvilinear grid cells in the main channel results in unrealistic flow patterns in sharp bends.

Based on the model performance criteria (computation time, accurate prediction of maximum water levels and accurate simulation of flow velocities in meander bends), we recommend to use a hybrid grid with curvilinear grid cells in the main channel and triangles in the floodplains for hydraulic 2DH modelling, since it combines the advantages of both a structured and unstructured grid. With a hybrid grid, it is possible to have a high resolution grid in the main channel, resulting in good representation of the bathymetry. The resolution in the floodplains can be much lower as a result of the triangular grid cells, which is beneficial for computation time. However, we found that a high width-length ratio of the curvilinear grid cells in the main channel results in unrealistic flow velocity patterns. We therefore conclude that from the six grids studied, the Hybr_LR grid is most beneficial in terms of overall model performance. 
Acknowledgements This research is supported by the Netherlands Organisation for Scientific Research (NWO, Project 14506) which is partly funded by the Ministry of Economic Affairs and Climate Policy. Furthermore, the research is supported by the Ministry of Infrastructure and Water Management and Deltares. This research has benefited from cooperation within the network of the Netherlands Centre for River Studies. The authors would like to thank the Dutch Ministry of Infrastructure for providing the data. Besides, the authors would like to thank Mrs. Becker and Mr. Van Dam from Deltares for their valuable insights. Finally, the authors would like to thank the two anonymous reviewers for their suggestions, which greatly improved the quality of the paper.

Open Access This article is distributed under the terms of the Creative Commons Attribution 4.0 International License (http://creativecommons.org/licenses/by/4.0/), which permits unrestricted use, distribution, and reproduction in any medium, provided you give appropriate credit to the original author(s) and the source, provide a link to the Creative Commons license, and indicate if changes were made.

\section{References}

1. Baker TJ (1996) Discretization of Navier-Stokes equations and mesh-induced errors. In: 5th international conference numerical grid generation in computational fluid simulation. Mississipi State University, Mississippi, USA

2. Bernard RS, Berger RC (1999) A parallel coupling scheme for disparate flow solvers. In: 1999 users group conference. Department of Defense, Monterey, California

3. Bridge JS (2003) Rivers and floodplains. Forms, processes and sedimentary record. Blackwell Science, Hoboken. https://doi.org/10.1002/jqs.856

4. Caviedes-voullième D, García-navarro P, Murillo J (2012) Influence of mesh structure on 2D full shallow water equations and SCS Curve Number simulation of rainfall/runoff events. J Hydrol 448(449):39-59. https://doi.org/10.1016/j.jhydrol.2012.04.006

5. Chow VT (1959) Open channel hydraulics. McGraw-Hill Book Company Inc, New York

6. Cobby DM, Mason DC, Horritt MS, Bates PD (2003) Two-dimensional hydraulic flood modelling using a finite-element mesh decomposed according to vegetation and topographic features derived from airborne scanning laser altimetry. Hydrol Process 17:1979-2000. https://doi.org/10.1002/ hyp. 1201

7. Deltares (2016) D-flow flexible mesh. Technical reference manual. Version: 1.1.0. Revision: 48665. Technical report, Deltares, Delft, The Netherlands

8. Deltares (2016) D-flow flexible mesh. User manual. Version 1.2.1. Technical report, Deltares, Delft

9. Hardy RJ, Bates PD, Anderson MG (1999) The importance of spatial resolution in hydraulic models for floodplain environments. J Hydrol 216:124-136

10. Harlow FH, Welch JE (1965) Numerical calculation of time-dependent viscous incompressible flow of fluid with free surface. Phys Fluids 8:2182. https://doi.org/10.1063/1.1761178

11. Heniche M, Secretan Y, Boudreau P, Leclerc M (2000) A two-dimensional finite element drying-wetting shallow water model for rivers and estuaries. Adv Water Resour 23:359-372

12. Horritt MS, Bates PD (2002) Evaluation of 1D and 2D numerical models for predicting river flood inundation. J Hydrol 268:87-99. https://doi.org/10.1016/S0022-1694(02)00121-X

13. Horritt MS, Bates PD, Mattinson MJ (2006) Effects of mesh resolution and topographic representation in 2D finite volume models of shallow water fluvial flow. J Hydrol 329:306-314. https://doi. org/10.1016/j.jhydrol.2006.02.016

14. Ikeda S, Parker G, Sawai K (1981) Bend theory of river meanders. Part 1. Linear development. J Fluid Mech 112:363-377. https://doi.org/10.1017/S0022112081000451

15. Jones JE (2002) Coastal and shelf-sea modelling in European context. In: Gibson RN, Atkinson RJA, Gordon JDM (eds) Oceanography and marine biology: an annual review, vol 40. CRC Press, Boca Raton, pp 37-141

16. Kernkamp HWJ, Van Dam A, Stelling GS, De Goede ED (2011) Efficient scheme for the shallow water equations on unstructured grids with application to the continental shelf. Ocean Dyn 61(8):1175-1188. https://doi.org/10.1007/s10236-011-0423-6

17. Kleptsova O, Pietrzak JD, Stelling GS (2009) On the accurate and stable reconstruction of tangential velocities in C-grid ocean models. Ocean Model 28:118-126. https://doi.org/10.1016/j.ocemo d.2008.12.007

18. Lai YG (2010) Two-dimensional depth-averaged flow modeling with an unstructured hybrid mesh. J Hydraul Eng 136(1):12-23. https://doi.org/10.1061/(ASCE)HY.1943-7900.0000134 
19. Lane SN, Hardy RJ, Elliott L, Ingham DB (2004) Numerical modeling of flow processes over gravelly surfaces using structured grids and a numerical porosity treatment. Water Resour Res. https://doi. org/10.1029/2002WR001934

20. Perot B (2000) Conservation properties of unstructured staggered mesh schemes. J Comput Phys 159:58-89. https://doi.org/10.1006/jcph.2000.6424

21. Schubert JE, Sanders BF, Smith MJ, Wright NG (2008) Unstructured mesh generation and landcoverbased resistance for hydrodynamic modeling of urban flooding. Adv Water Resour 31(12):1603-1621. https://doi.org/10.1016/j.advwatres.2008.07.012

22. Sleigh PA, Gaskell PH, Berzins M, Wright NG (1998) An unstructured finite-volume algorithm for predicting flow in rivers and estuaries. Comput Fluids 27(4):479-508. https://doi.org/10.1016/S0045 $-7930(97) 0071-6$

23. Stelling GS (1983) On the construction of computational methods for shallow water flow problems. Ph.D. thesis, Technical University of Delft. http://resolver.tudelft.nl/uuid:d3b818cb-9f91-4369-a03ed90c8c175a96. Accessed 14 Feb 2017

24. Sukhodolov AN (2012) Structure of turbulent flow in a meander bend of a lowland river. Water Resour Res 48:1-21. https://doi.org/10.1029/2011WR010765

25. Verwey A, Kernkamp HWJ, Stelling GS, Tse ML, Leung WC (2011) Potential and application of hydrodynamic modelling on unstructured grids. In: Proceedings of the sixth international conference on Asian and pacific coasts (APAC). Hong Kong, China

26. Ye J, McCorquondal JA (1997) Depth-averaged hydrodynamic model in curvilinear collocated grid. J Hydraul Eng 123(5):380-388

Publisher's Note Springer Nature remains neutral with regard to jurisdictional claims in published maps and institutional affiliations. 